\title{
Movimentos Sociais e Educação no Brasil: a Conjuntura de 2013 a 2018
}

Social Movements and Education in Brazil:

The Conjuncture from 2013 to 2018

Movimientos sociales y educación en Brasil: la coyuntura del 2013 al 2018

Maria Antônia de Souza* (iD orcid.org/0000-0001-7514-8382

Para citar este artículo: de Souza, M. (2021). Movimentos Sociais e Educação no Brasil: a Conjuntura de 2013 a 2018. Revista Colombiana de Educación, /(81), 289-310. https://doi.org/10.17227/rce.num81-10598

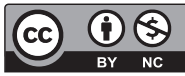




\section{Resumo}

Este trabalho caracteriza movimentos e manifestações sociais vinculadas à educação no Brasil de 2013 a 2018, período de elaboração do Plano Nacional de Educação e de manifestações de docentes e estudantes. É fruto de pesquisa documental, cujo substrato é composto por documentos da sociedade civil, como cartas e manifestos do Fórum em Defesa da Escola Pública, Sindicato Nacional de Docentes das Instituições de Ensino Superior, Associação Nacional de Pós-Graduação, leis, decretos e medidas provisórias. Referencia-se em obra de Gohn (1997), para quem os movimentos sociais expressam ações de natureza sociopolítica e são construídos por sujeitos coletivos de diferentes classes e camadas sociais. As ações são articuladas aos cenários conjunturais do país. De acordo com essa perspectiva, no Brasil há predominância de ações coletivas que lutam pelo fortalecimento de práticas democráticas e educação pública no período analisado,. Constata-se, no país, com as manifestaçōes de 2013, a repolitização dos movimentos sociais, marcada por ações coletivas que se inspiram em velhas utopias e outras que se sustentam na ideologia conservadora.

\section{Palavras-chave}

educação; educação pública; participação; organizações sociais; democracia

\section{Keywords}

education; public education; participation; social organizations; democracy

\begin{abstract}
This article characterizes movements and social manifestations linked to education in Brazil from 2013 to 2018. During this period the National Plan of Education was issued, and teachers and students organized different manifestations. The paper is the result of a documentary research, with a corpus consisting of civil society documents, such as letters and manifests from the Forum in Defense of the Public School, National Union of Teachers of Higher Education Institutions, National Association of Postgraduate and Research in Education and National Meeting of Education of 2016, along with laws, decrees and provisional measures. It is based on Gohn (1997), for whom social movements are sociopolitical actions built by collective social actors belonging to different classes and social strata. The actions are articulated in certain sceneries of the political conjuncture of the country. According to this perspective,there is a predominance of collective actions that struggle for the strengthening of democratic practices and public education in the analyzed period in Brazil. It might be concluded that, in the country, with the manifestations of 2013, the repoliticization of social movements becomes evident, marked by collective actions inspired by old utopias and other ones based on the conservative ideology.
\end{abstract}

\section{Resumen}

Este trabajo caracteriza los movimientos y manifestaciones sociales vinculados a la educación en Brasil del 2013 al 2018, periodo de elaboración del Plan Nacional de Educación y de manifestaciones de docentes y estudiantes. Es el resultado de una investigación documental, cuyo sustrato está compuesto por documentos de la sociedad civil tales como cartas y manifiestos de los foros en Defensa de la Escuela Pública, Sindicato Nacional de los Docentes de las Instituciones de Enseñanza Superior, la Asociación Nacional de Posgrados e Investigación en Educación y el Encuentro Nacional de Educación 2016, junto a las leyes, decretos y medidas provisorias. Se refiere a Gohn (1997), para quien los movimientos sociales son acciones sociopolíticas construidas por actores sociales colectivos pertenecientes a diferentes clases y estratos sociales que se articulan en determinados escenarios de la coyuntura política de un país. Desde esta perspectiva en Brasil predominan las acciones colectivas que luchan por el fortalecimiento de las prácticas democráticas y la educación pública en el periodo analizado. Es posible concluir que, en el país, con las manifestaciones del 2013, se nota la repolitización de los movimientos sociales, marcada por acciones colectivas que se inspiran en viejas utopías y otras que se basan en la ideología conservadora.

\section{Palabras clave}

educación; educación pública; participación; organizaciones sociales; democracia 


\section{Introdução}

O Brasil é um país marcado por movimentos sociais no campo e na cidade. Lutas por democracia e por eleições diretas tiveram visibilidade no final do século xx, com aprovação do texto constitucional de 1988, positivando direitos sociais, políticos e civis. Nesse período, o movimento de luta pela terra, pela reforma agrária estava no auge, com a atuação do Movimento dos Trabalhadores Rurais Sem Terra (MST). Também, lutas em torno da educação pública, gratuita, laica e de qualidade foram registradas a partir das ações do Fórum Nacional em Defesa da Escola Pública (FNDEP).

A pesquisadora Maria da Glória Gohn analisa os protestos, movimentos e as manifestações sociais no país, em várias conjunturas políticas. Em suas obras demonstra a variedade de lutas, desde movimentos organizados para a libertação política do país, passando por movimentos de camponeses, movimentos populares urbanos até os protestos organizados a partir de redes sociais e digitais. Identifica uma diversidade de movimentos populares urbanos, incluindo lutas por acesso a moradia, creches, escolas, transporte, saúde, condições de trabalho etc.

Em 1996 foi aprovada a Lei de Diretrizes e Bases da Educação Nacional (LDB sob $n^{\circ}$ 9.394/1996), positivando direitos de jovens e adultos, pessoas com necessidade educativas especiais e indígenas, no conjunto das disposições sobre a Educação Básica, Superior e Pós-Graduação. Continuaram a existir lutas e demandas pelo reconhecimento de segmentos como os Quilombolas e povos do campo, que culminaram na aprovação de diretrizes educacionais ao longo da primeira década do século xxı e na organização de programas governamentais específicos.

As lutas por escolas públicas no/do campo integram o conjunto de demandas por educação, em sua concepção ampla, para áreas de assentamentos e acampamentos do MST. A experiência coletiva dos movimentos sociais constrói a concepção da Educação do Campo a partir do final de 1990.

Diante dessas marcas da sociedade brasileira e tomando como referência a pesquisa documental, o propósito deste texto é caracterizar as demandas dos coletivos de trabalhadores em torno da educação. Esses coletivos caracterizam-se como organizações sociais, entidades de classe e associações que fortalecem os movimentos sociais de lutas por educação pública com as suas ações coletivas. A escolha do período de 2013 a 2018 ocorre em função de que o ano de 2013 no Brasil ficou conhecido pelas manifestações vinculadas a problemas do transporte urbano, temáticas vinculadas aos investimentos na construção de estádios para os jogos da Copa de 2014, à corrupção e à permanência das desigualdades sociais. No ano de 2014 foi aprovada a Lei sob no 13.005 de 2014 que institui o 
Plano Nacional de Educação para o período de dez anos, depois de muitas disputas políticas em torno do financiamento da educação, educação a distância e privatização do ensino. Em 2015, destacam-se as organizações coletivas de estudantes e os debates do Fórum Nacional de Educação do Campo (FONEC) sobre educação pública, políticas públicas e projeto de campo, entre outros. Em 2016 e 2017 há visibilidade das críticas sobre o empresariamento da educação, a Base Nacional Comum Curricular (BNCC), a reforma do Ensino Médio, o Projeto Escola Sem Partido, o corte de verbas para educação, muitas delas feitas pelas associações e entidades científicas, dentre elas a Associação Nacional de Pós-Graduação e Pesquisa em Educação (ANPED). Por fim, 2018 como ano marcado por debates conjunturais, manifestações contra a prisão do ex-presidente Lula e contra a Medida Provisória $n^{\circ} 65$ de 31 de maio de 2018 que diminui os recursos para educação, reforma agrária, agricultura familiar entre outras áreas. Ainda, foi o ano de realização da Conferência Nacional Popular de Educação (CONAPE) e do Encontro dos 20 anos da Educação do Campo e do PRONERA, promovido pelo FONEC. Embora tenha sido um ano de participação popular e resistências, também ficou marcado pela organização de grupos conservadores no espaço público, que fizeram uso das redes sociais com fake News e aguçaram o imaginário da sociedade com ideias conservadoras e contrárias ao Partido dos Trabalhadores-

É uma conjuntura de seis anos marcada por enfrentamentos políticos e pelo que ficou conhecido como Golpe de 2016, do ponto de vista jurídico-midiático-parlamentar, que retirou a presidente eleita Dilma Rousseff e coroou, em meio a protestos, Michel Temer na presidência da República. Desse período em diante tem havido golpes para a área social no país, a começar pelo rompimento com os diálogos entre os segmentos do governo e a sociedade civil (leia-se classe trabalhadora), predominantes nos de Lula da Silva e Dilma Rousseff. A partir do golpe, os diálogos do governo vêm sendo estabelecidos com o setor empresarial, inclusive na área da educação. Conjuntura de expressiva contradição, de acirramento dos embates de classe, disputas político-judiciais e revelação de que há uma cultura política conservadora historicamente predominante no país. Presença de discurso maquiado por palavras de natureza democrática, porém com prática política autoritária, judicializada e com ênfase na criminalização dos protestos, manifestos e movimentos sociais. Discursa-se sobre a importância do conhecimento, porém criminaliza-se o trabalho docente mediante argumentos vinculados ao ideário da neutralidade científica e política. Discursa-se sobre conhecimento e cidadania, porém criam-se mecanismos para inibir e fragilizar o debate crítico que, por sua vez, pressupõe enfrentamentos e construção de argumentos com conteúdo histórico, evidenciando contradição, ideologia e as disputas políticas. 
Este trabalho tem como referência documentos de encontros nacionais, em especial os vinculados à educação do campo, relatórios, pautas e manifestos do FNDEP, do Sindicato Nacional de Docentes do Ensino Superior (ANDES), da ANPED, e documentos do Fórum Nacional Popular de Educação (FNPE) e do FONEC.

Os fundamentos teóricos pautam-se nos conceitos de movimentos sociais, direito e educação em perspectiva popular. A respeito do conceito de movimentos sociais, a referência é Gohn (1997, p. 251) para quem os "Movimentos são ações sociopolíticas construídas por atores sociais coletivos pertencentes a diferentes classes e camadas sociais, articuladas em certos cenários da conjuntura socioeconômica e política de um país, criando um campo político de força social na sociedade civil [...]". Para a mesma autora, eles ser referem a "[...] ações sociais coletivas de caráter sociopolítico e cultural que viabilizam distintas formas da população se organizar e expressar suas demandas" (Gohn, 2003, p. 13). Os coletivos, na ação concreta, adotam diferentes estratégias de lutas que variam da simples denúncia até as manifestações, marchas, passeatas, negociações entre outros formatos de pressão. Desde o final do século xx, os movimentos sociais atuam por meio de redes sociais locais, regionais, nacionais e internacionais, mediante uso do âmbito das tecnologias digitais de informação e comunicação.

Analisando as manifestações de 2013, Gohn (2013, p. 8) escreve que: "os acontecimentos ocorridos no Brasil em junho de 2013 foram denominados pela mídia e outros como 'manifestações', ficando este termo como um marco na memória do país". A referida autora escreve que as jornadas, atos, onda, protesto de massa, mobilizações, revoltas etc. são outras expressões utilizadas para tratar das cenas no espaço público, algo que ela compreende como "movimento dos indignados". Ou seja, são manifestações de indignação em face da conjuntura política nacional.

Os manifestantes de junho no Brasil atuam em coletivos não hierárquicos, com gestão descentralizada, produzem manifestações com outra estética; os participantes têm mais autonomia, não atuam sob a coordenação de uma liderança central. São movimentos com valores, princípios e formas de organização distintas de outros movimentos sociais, a exemplo dos sindicais, populares (urbanos e rurais), assim como diferem dos movimentos identitários (mulheres, quilombolas, indígenas etc.). (Gohn, 2013, p. 9).

Sobre direitos, a investigação partiu da compreensão do protagonismo dos sujeitos, conflitos, disputas e antagonismos na cena pública, seguindo os ensinamentos de Telles (2006), quando destaca que os sujeitos colocam à prova os princípios universais dos direitos. Para autora: 
As possibilidades do campo democrático construído nos últimos anos parecem, hoje, na segunda metade da década de 90, desafiadas por um projeto conservador que já se traduz em práticas reais, no qual a neutralização da dimensão ética da justiça e da igualdade em nome dos critérios de eficácia e racionalidade técnica da economia, passa pela imposição de uma ordem pública subtraída das esferas políticas de representação, negociação e interlocução. (Telles, 2006, p. 186).

Sobre desigualdade, entende-se que, como explicita Wanderley (2000, p. 58), a questão social fundante no país e na América Latina se centra nas desigualdades e injustiças enraizadas na estrutura social e resultante dos modos de produção e reprodução social, dos modos de desenvolvimento que se formaram em cada sociedade nacional. Segundo o autor, a questão social:

[...] se funda nos conteúdos e formas assimétricos assumidos pelas relações sociais, em suas múltiplas dimensões econômicas, políticas, culturais, religiosas, com acento na concentração de poder e de riqueza de classes e setores sociais dominantes e na pobreza generalizada de outras classes e setores sociais que constituem as maiorias populacionais cujos impactos alcançam todas as dimensões da vida social, do cotidiano às determinações estruturais. (2000, p. 58).

O Brasil é um país de contrastes sociais expressivos, sejam eles de natureza econômica ou sociocultural. A classe trabalhadora enfrenta as faces da desigualdade social e conquista, paulatinamente, o direito de falar, de dizer a palavra no sentido de criticar, propor e acompanhar as políticas educacionais. Os jovens secundaristas (Ensino Médio) demonstraram a capacidade de organizar a ocupação das escolas e de desmascarar discursos de muitos governantes estaduais. Os camponeses lutam há séculos pelo protagonismo político na efetivação da reforma agrária.

No Brasil, nos últimos 20 anos, a classe trabalhadora acessou a Educação Superior por meio de políticas como a de Cotas e programas Como PRONERA (Programa Nacional de Educação na Reforma Agrária), PROCAMPO (Programa de Apoio à Formação Superior em Licenciatura em Educação do Campo) e a criação dos Institutos Federais de ensino médio e superior em regiões interioranas do Brasil.

Necessário lembrar que desde a década de 1990 tem havido ampliação do número de instituições privadas de ensino no país, em especial na Educação Superior. No período de 2016 a 2018 foram criadas 127 instituições privadas de Educação Superior, sendo 3 universidades, 64 Centros Universitários e 61 faculdades. Quanto às públicas, no mesmo período foram constituídas 3 instituições públicas. Levantamento realizado junto ao Instituto Nacional de Estudos Educacionais Anísio Teixeira indica que o Brasil possui 2.537 instituições de Educação Superior, sendo 904 
localizadas em capitais e 1.633 no interior do país. Do total de IES (2.537), 299 são públicas (110 federais, 128 estaduais e 61 municipais) e 2.238 são privadas. Importante é verificar o status da instituição de Educação Superior. Do conjunto de 2.537 instituições, 199 são universidades e dentre elas 107 são públicas (63 federais, 40 estaduais e 4 municipais) e 92 são universidades privadas. Centros Universitários são 230 no país, sendo 13 públicos (2 federais, 2 estaduais e 9 municipais) e 217 privados. Por fim, 2.068 instituições são faculdades, das quais 139 são públicas (5 federais, 86 estaduais e 48 municipais) e 1.929 são privadas. (Brasil, 2018)

Essa realidade de predominância de IES privadas gera demandas e disputas políticas por recursos orçamentários e aprovação de legislação e diretrizes que atendam interesses do setor empresarial. Após o Golpe de 2016, as desigualdades educacionais tendem a se agravar, em função de cortes orçamentários de bolsas de estudos, cortes de recursos para projetos de pesquisas que articulam educação superior e educação básica entre outros. Denúncias sobre a desvalorização da educação têm sido feitas nos coletivos nacionais e regionais, sindicais e das sociedades acadêmico-científicas.

A fragilização de direitos recém-conquistados na área educacional, a exemplo da Educação do Campo, é processo que se inicia nos anos de 2014, com a criação do Movimento Brasil Livre (MBL), de caráter político, conservador e privatista. No documento intitulado "Propostas aprovadas no $1^{\circ}$ Congresso Nacional do Movimento Brasil Livre", realizado em novembro de 2015, fica explícito o caráter privatista defendido para a educação, bem como o uso da repressão quando necessária. O Movimento também defende o fim da função social da propriedade. Em estreito vínculo com O MBL foram criados projetos de leis em estados, municípios e no âmbito federal, conhecidos como "Escola Sem Partido".

De um lado os sujeitos coletivos que defendem a educação pública, crítica e a universalização do acesso à educação superior. De outro lado há coletivos que defendem a privatização e a regulação dos conteúdos escolares, em nome da neutralidade científica e da qualidade da educação. Esse segmento vincula-se ao Movimento Brasil Livre e aos defensores dos projetos de lei intitulados "Escola Sem Partido". Como escreve Gohn (2017, p. 88), também, o movimento "Compromisso Todos pela Educação" é um exemplo de novo movimento social na área da educação.

É uma coalização de pessoas do mundo empresarial e/ou das elites empresariais, tais como G. Gerdau, J. Roberto Marinho, ou executivos de grandes bancos e personalidades do Terceiro Setor, com destacada atuação no campo da Educação, como Viviane Senna, Milu Vilela, Norberto Pascoal etc., além do Instituto Ethos, e o Gife, com apoio da unEsco. A proposta é no sentido de fazer da Educação uma ferramenta básica para o próprio desenvolvimento do País, pressionando o governo para que ela se torne a principal política pública. 
E, segundo a autora, há um novo ciclo de lutas na educação, em um cenário de questões sobre currículo e educação básica, com ênfase no Ensino Médio. Para ela,

O Movimento Contra a Escola Sem Partido é um dos exemplos a ser citado. Escola sem Partido é um projeto controverso - apoiado pelos setores retrógrados da sociedade, que defendem abertamente valores anti-democráticos - e tem sido amplamente discutido e questionado [...]. (Gohn, 2017, p. 90).

Nesse movimento não há lugar para a participação popular. Há disputas por verbas públicas para a iniciativa privada e há determinação e vigilância jurídicas em relação à participação dos coletivos de trabalhadores nos debates e no controle social das políticas.

Fica configurada uma disputa política em torno de um direito social. Disputa que integra o jogo internacional do capital. Afinal, a quem interessa que os conteúdos de análise de conjuntura, as contradições sociais, as condições precárias de trabalho etc. não sejam discutidos? A quem interessa que os professores sejam técnicos do ensino? A quem interessa a fragilização do conhecimento?

Projetos como o Escola Sem Partido negam a construção social da Educação Popular no país e criminalizam os movimentos sociais e o seu protagonismo na efetivação de direitos, na proposição e acompanhamento de políticas públicas. A Educação Popular tem como princípio a educação construída na prática coletiva e com a finalidade voltada para a transformação social.

Do ponto de vista da educação popular, Paulo Freire e Carlos Rodrigues Brandão são protagonistas centrais no Brasil, por suas produções e participação em coletivos de formação político-pedagógica. Como afirmam Souza e Beltrame (2017, p. 101): "As contribuições de Paulo Freire foram fundamentais no sentido de propor uma educação que não se limitasse somente ao contexto escolar, mas que dialogasse com as relações sociais, possibilitando uma "educação libertadora" e organizativa dos diferentes movimentos sociais".

Estudos de Paludo (2015, p. 228) contribuem para a divulgação do alcance político-pedagógico que as ações educacionais conquistaram na sociedade. Para ela:

As expressões povo sujeito de sua história, autonomia, conscientização, organização, protagonismo popular, luta e transformação indicavam a orientação das práticas, assim como o "fazer com", trabalhado conceitualmente como práxis e por vezes como o movimento permanente entre prática-teoria-prática, ver-julgar-agir ou ação-reflexão-ação, era considerado a lógica metodológica, permeada pela relação 
entre os saberes populares e o conhecimento historicamente acumulado, pela sistematização, pela pesquisa-ação participante e pelo diálogo, que orientava os métodos, técnicas e procedimentos, incluindo os processos avaliativos, dos múltiplos processos e práticas educativas que se instauraram na América Latina (2015, p. 228).

São inúmeras as experiências de Educação Popular no país, de natureza contra-hegemônica em sua essência. Movimentos sociais da classe trabalhadora, organizações, grupos de pesquisas universitários entre tantos, constituem exemplos de construção de processos formativos fundados na preocupação com a emancipação humana, portanto, revolucionária. O Movimento Nacional de Educação do Campo, conforme denominado por Munarim (2008), retoma princípios da Educação Popular e da educação revolucionária.

Tomando como referência esse cenário conjuntural, o texto estrutura-se na exposição de sujeitos coletivos e de espaços públicos presentes no referido período, priorizando segmentos da sociedade civil organizada, especialmente a vinculada à classe trabalhadora. Sujeitos e cenários públicos são elementos importantes para a compreensão de movimentos, manifestações e protestos sociais. Por meio de palavras de ordem, cartas e manifestos, fazem críticas à precarização de direitos e à condição de desigualdade das maiorias.

\section{Os sujeitos coletivos e movimentos de lutas por educação pública, gratuita, laica e de qualidade}

O sujeito coletivo mencionado neste texto é aquele que diz da sua realidade, da materialidade vivida, para além dos discursos positivados na legislação. Quando o sujeito (objeto de discursos igualitários) entra em cena revela o que escreve Telles (2006, p. 180):

O que desestabiliza consensos estabelecidos e instaura o litígio é quando esses personagens comparecem na cena política como sujeitos portadores de uma palavra que exige o seu reconhecimento [...] que se pronunciam sobre questões que lhes dizem respeito, que exigem partilha na deliberação de políticas que afetam suas vidas e que trazem para a cena pública o que antes estava silenciado, ou então fixado na ordem do não pertinente para a deliberação política.

Tomando como referência essa ideia de sujeito e de protagonismo social, a opção foi por selecionar cinco sujeitos coletivos e suas lutas em torno do direito à educação. São eles: O FNDEP constituído em 1986; a ANPED criada em 1978; o FONEC criado em 2010; o movimento dos estudantes das escolas 
públicas, que ficou conhecimento como "Ocupa Escola", no ano de 2016; por fim, o FNEP criado no ano de 2017, congregando entidades da educação, da classe trabalhadora, antes pertencente ao Fórum Nacional de Educação.

O FNDEP ficou conhecido nos anos de 1980 pela defesa da educação como direito de todo o cidadão, pela luta pela redemocratização da sociedade e por verbas públicas para a Educação. Foi um dos responsáveis pela elaboração do projeto de LDB integrando as pautas da sociedade civil, em especial, das vozes dos sujeitos que diziam da educação necessária a eles. É um dos coletivos de luta pela constituição do Sistema Nacional de Educação, gestão democrática em todas suas instâncias e nas unidades educacionais, participação e controle da/pela sociedade. A partir de 2011 fortaleceu as reivindicações em relação ao Plano Nacional de Educação, aprovado em 2014, composto de 20 metas e diversas estratégias. No Plano verifica-se o reconhecimento de questões pautadas pelos movimentos sociais do campo, indígenas, quilombolas, jovens e adultos entre outros. Em que pese as estratégias vincularem-se às demandas postas pelos coletivos de trabalhadores, a redução e congelamento de verbas para a educação pública não permitirão, em dez anos, a efetivação da educação em perspectiva crítica e universal.

Conforme escreve Souza (2017), enquanto países da América Latina, como Chile, lutam pela retomada da educação pública pelo vínculo do Estado, o Brasil retrocede e difunde discursos sobre a precarização das universidades públicas induzindo a população a pensar que a educação particular será a salvação. Os movimentos sociais de trabalhadores que resistem são "abafados" pela mídia, que compactua com os interesses do capital nacional e internacional.

A ANPED, ${ }^{1}$ por sua vez, conforme escreve Souza $(2019$, p. 9) tem sido combatente das políticas de empresariamento da educação, da Reforma do Ensino Médio, do Projeto Escola Sem Partido e da ausência de diálogo com o governo federal. Essa associação tem realizado debates com intelectuais da educação brasileira e interlocução com movimentos e organizações sociais voltadas para a valorização da educação pública, da produção do conhecimento científico e argumentação de críticas aos projetos que congelam os investimentos sociais, em particular na educação. Para a entidade, segundo a autora supracitada, o "Programa Escola sem Partido", por exemplo, está mascarado no discurso de neutralidade, na tentativa de institucionalizar o cerceamento da liberdade de expressão e de ensino nas escolas brasileiras. Trata-se de um "[...] projeto traz a aparência de proteção às crianças e jovens, às famílias, mas trata-se da expressão conservadora presente no país, em várias frentes na educação." (Souza, 2019, p. 9).

1 Acesse a página http://www.anped.org.br e encontre artigos, cartas e manifestos favoráveis à educação pública. Acesso em 30 de junho de 2018. 
O FONEC tem como um dos expoentes o MST por suas experiências e lutas por educação dos povos do campo. O MST2 $^{2}$ tem colocado a educação em debate desde meados dos anos de 1980, quando criou o Setor de Educação, pautando as escolas dos assentamentos, a educação das crianças dos acampamentos, a formação de professores, o currículo entre outros temas e problemas vividos no campo. Das experiências do MST foram constituídos o Movimento Nacional de Educação do Campo, as políticas educacionais e as diretrizes curriculares vinculadas aos povos do campo, das águas e das florestas. Em 2011, o MSt lançou a Campanha "Fechar escola é crime", como forma de resistir à política de fechamento de escolas públicas no campo. Portanto, o FONEC, e com ele o MST, tem marcado posição contra o empresariamento da educação, a favor da educação pública e universalização do acesso à Educação Básica, Superior e Pós-Graduação. Ao lutar por educação do campo, interroga o projeto de campo e de agricultura em vigência no país. Defende educação segundo a perspectiva da emancipação humana e pautada pelos princípios da agroecologia. Esses posicionamentos são reiterados no FONEC desde sua criação no ano de 2010.

O Movimento de Ocupação das Escolas, no ano de 2016, foi marcado pela ação dos estudantes secundaristas (Ensino Médio). A juventude estudantil, nas centenas de ocupações realizadas em escolas e universidade públicas alertava para o fato de que o ensino público enfrenta dificuldades que são de infraestrutura precária, desvalorização dos professores e baixos salários. Os estudantes criticaram a reforma do Ensino Médio pela desvalorização imposta à área de humanas na organização curricular. A política de fechamento de escolas públicas, denunciada em 2011 pelo MST, atinge espaços urbanos como São Paulo, desencadeando uma série de denúncias e a ação de ocupar escolas para dizer da situação vivida e da recusa às políticas "de cima" implantadas por governos estaduais, municipais e federal.

O movimento "Ocupa Escola" direcionou suas críticas ao segmento governamental que apresentava propostas contrárias aos anseios e necessidades da juventude e à realidade das escolas públicas no Brasil. Movimento organizado a partir de comissões de trabalho de modo a garantir a convivência e organização coletiva nas escolas durante a ocupação. Fizeram articulação com coletivos como universitários, movimentos sociais de diversos segmentos como negros, LGBT, MST entre outros.

2 Na página do mst - http://www.mst.org.br - é possível encontrar publicações e bandeiras de luta em torno da Educação e da Escola. Acesso em 30 de junho de 2018. 
Como afirma Gohn (2017, p. 90), "As reivindicações dos/as estudantes são diversas, mas as três pautas em comum, que têm ganhado muita força, são a Base Nacional Comum Curricular, o debate de gênero nas escolas e a livre organização estudantil". Para a autora:

Nas ocupações do Brasil os estudantes tiveram como fonte de inspiração o movimento pela educação ocorrido anos atrás no Chile, tanto na chamada "Revolta dos Pinguins" da década de 2000 como nas ocupações que vieram ocorrendo em 2010, no Chile e na Argentina. Cartilhas e matérias sobre como fazer e como organizar uma ocupação foram meios para difundir aqueles ideais. (Gohn, 2017, p. 90).

Em muitos momentos, o movimento "Ocupa Escola" lembrou as ações do MSt do início dos anos de 1990, período em que o movimento deu visibilidade à palavra de ordem "Ocupar, Resistir e Produzir também na Educação", fortalecendo o lema vinculado a reforma agrária que era "Ocupar, Resistir e Produzir". A juventude do movimento "Ocupa Escola" deu visibilidade ao lema "Ocupar e Resistir".

O movimento Ocupa Escola ficou conhecido por sua organização e politização. Seus cartazes revelam que os opositores, naquele momento, eram os governantes. Alguns temas presentes em cartazes de diversos estados brasileiros continham o que segue: "Você fecha minha escola e eu tiro o seu sossego". Frase direcionada ao governador de São Paulo - Geraldo Alckmin, como forma de resistir ao fechamento de escolas nos anos de 2015 e 2016. - "Os jovens também ensinam". - "Lutar sempre, Temer jamais". Uma crítica expressa ao Michel Temer que assume a presidência da República após o impeachment de Dilma Rousseff. - "Contra o golpe do Ensino Médio, fora Temer". - "O jovem no Brasil nunca é levado a sério". - "O governo não quer dar educação porque educação derruba o governo". - "A escola é nossa". - "Educação não é mercadoria". (Souza, 2017, p.10)

O FNPE, criado em 2017, constitui-se como sujeito coletivo que conquista lugar e visibilidade no cenário das lutas por educação, composto por 35 entidades. Conforme escreve Souza (2019, p. 19), com o FNPE, a Conferência Nacional Popular de Educação torna-se espaço público para o debate educacional e como forma de enfrentamento e resistência em relação às ações do governo federal no âmbito social. Essa conferência dá sequência às práticas coletivas inauguradas nas décadas de 1980 e 1990, com o conjunto de conferências conhecido como: Conferência Brasileira de Educação (СBE); Conferência Nacional de Educação (pós aprovação da LDB 9.394/96); Conferência Nacional de Educação Brasileira (CNEB) no ano de 2008; e as Conferências Nacionais de Educação (CONAEs) de 2010 e 2014.

Nesse cenário, como se constrói o Fórum Nacional de Educação Popular (2017) e a Conferência Nacional Popular de Educação? Importante lembrar o desmonte que o Ministério da Educação realizou na estrutura 
do Fórum Nacional de Educação (FNE) previsto na Lei 13.005 de 2014 que institui o plano nacional de educação para o período de dez anos. Em abril de 2017, mediante a portaria sob nº 577, o Ministério da Educação excluiu entidades da composição do FNE e atribuiu ao Ministro da Educação o poder de definir a composição do referido fórum. Além disso, o governo federal deixou de financiar a Conferência Nacional de Educação que se realizaria em 2018.

Com esses acontecimentos, diversas entidades da sociedade civil deixaram o FNE e criaram o Fórum Nacional Popular de Educação (FNPE), organizando, assim, o espaço público da Conferência Nacional Popular de Educação (CONAPE, 2018), realizada em maio do mesmo ano na cidade de Belo Horizonte/MG. A CONAPE, segundo o regimento da etapa nacional, "possui caráter mobilizador, de luta e resistência na defesa da democracia e apresentará um conjunto de propostas relativas ao monitoramento e avaliação e à efetiva implementação do Plano Nacional de Educação [...]". (CONAPE, 2018, p.1)

O coletivo nacional reafirma-se como "[...] uma convocação à retomada da democracia no país e das vozes da sociedade civil organizada por meio dos movimentos sociais e das entidades educacionais; uma reafirmação do compromisso com uma educação verdadeiramente transformadora" (CONAPE, 2017, p. 2).

De acordo com Souza (2019, p. 20), somam-se a esses sujeitos coletivos, o Sindicato da Associação Nacional de Docentes do Ensino Superior (ANDES), criado em 1981. É um sindicato que tem reafirmado os compromissos de: - Lutar pela educação pública de qualidade, pela valorização do trabalho docente e pela autonomia das instituições públicas de ensino superior; - Lutar pela universalização do acesso à educação superior pública e gratuita, com garantia de permanência; - Lutar contra as reformas neoliberais que retiram direitos dos trabalhadores, especialmente a reforma universitária privatizante; - Combater todas as formas de mercantilização da educação.

Em síntese, pode-se afirmar que houve um período de fortalecimento de práticas democráticas, especialmente no período de 2003 a 2015, quando a conjuntura política favorecia a participação popular no país. O ano de 2016 representa um momento difícil para a manutenção das conquistas coletivas, que até então eram fortalecidas por meio de audiências públicas, de comissões interministeriais e comissões que integravam representantes da sociedade civil e dos governos. A judicialização da educação ganha lugar tanto para gerar denúncias e conquistas relacionadas ao direito à educação, como para interrogar a política de Cotas, ou os programas educacionais vinculados à reforma agrária entre outros. Em nome do princípio da igualdade formal interroga-se a efetivação de políticas voltadas para o direito à igualdade fática. 
No período de 2016 a 2018, as reuniões técnicas das equipes governamentais com os movimentos sociais foram diminuídas, extintas ou silenciadas, dando lugar às assessorias empresariais na construção da política educacional. Negociações relacionadas à educação passaram a ser feitas com assessoria empresarial e voltada para atender interesses do mercado. Assim, foram impostas reformas como a do Ensino Médio e gerados conflitos em torno de temas como gênero, sexualidade, escola e partidos políticos, ideologia entre outros.

A educação está no cenário das disputas políticas e os avanços dependem da organização da sociedade e do fortalecimento dos movimentos sociais, das organizações e entidades acadêmico-científicas.

\section{Os espaços públicos: conferência nacional popular de educação e encontro dos 20 da educação do campo e do pronera (junho de 2018)}

Os espaços públicos são caracterizados pela presença dos sujeitos coletivos, reunidos para discussão sobre projeto de país, políticas sociais e educacionais, críticas aos encaminhamentos governamentais que fortalecem a participação empresarial na prestação de serviços e na condução das políticas. Espaços públicos são marcados por marchas, manifestações, ocupações de praças públicas e prédios públicos, conferências sindicais e universitárias. Neles há a disputa por projetos políticos, em uma conjuntura de retomada dos princípios neoliberais dos anos de 1990, como a privatização do patrimônio público e a depreciação dos serviços públicos, a exemplo da saúde e educação.

No ano de 2016, de acordo com Souza (2019, p. 18), o Encontro Nacional de Educação reuniu milhares de pessoas em Brasília, entre estudantes, professores, comunidades, movimentos, organizações etc. Fez a defesa da educação pública, gratuita, democrática e de qualidade em todos os níveis de ensino, e que seja acessível para toda a população. Enfatizou a perspectiva da emancipação humana no processo formativo e, consequentemente, uma formação que possibilite pensamentos e experiências voltadas para construção de outro tipo de sociedade. Na compreensão de Telles (2006, p. 190), em cenários públicos abertos à palavra do direito são desconstruídas a figuração da pobreza e da negatividade. Os coletivos dizem o que desejam, para além dos discursos sobre igualdade e justiça que constroem a figura do pobre.

As reflexões feitas por Souza (2019, p. 15 - 16) indicam que, no período governamental de 2003 a 2015, aconteceram audiências públicas, fóruns em defesa da educação, comissões interministeriais, comissões formadas por governos e sociedade civil. Leia-se a sociedade civil constituída 
pelos coletivos marcadamente da classe trabalhadora. Entretanto, a partir de agosto de 2016 as políticas educacionais são pautadas por diálogos entre governo e empresa, com interrupção de comissões interministeriais nas áreas em que os sujeitos haviam conquistado vozes, coletivos que podiam dizer da sua existência e participar da construção de políticas efetivas. Os coletivos empresariais são fortalecidos na sociedade civil e na relação com os governos. Assim, alargam-se, também as disputas, resistências e enfrentamentos para evitar perda de direitos e fragilização de políticas construídas com a participação social. As estratégias de resistência foram realizadas nas ruas e escolas. Da participação social resultaram inúmeros documentos conhecidos como Cartas e Manifestos contrários às ações governamentais de face conservadora, instalada na gestão do governo de Michel Temer, a partir de meados de 2016.

Neste texto destacam-se dois espaços públicos expressivos da luta por educação transformadora, na resistência contra atitudes governamentais autoritárias e na oposição ao empresariamento da educação. Trata-se dos espaços públicos construídos pelo FNPE e pelo FONEC, que produziram manifestos e planos de lutas de resistência e de proposição.

O documento final da CONAPE (FNPE, 2018, p. 1 - 18) traz um plano de lutas composto por 14 itens, a saber:

1. Pela revogação dos decretos que retiram do FNE sua base de representação social e descaracterizam a CONAE-2018 - contra a interferência autoritária do MEC.

2. Pela organização de um Sistema Nacional de Educação com regulamentação da Educação privada - contra a atuação do setor privado na educação sem a garantia da qualidade e sem a valorização de seus trabalhadores.

3. Pela garantia de condições de qualidade socialmente referenciada por meio de articulação federativa das políticas educacionais democraticamente construídas.

4. Pelo respeito à diversidade e pela construção democrática da proposta curricular das escolas - contra a padronização do currículo e o modelo de gestão empresarial nas escolas.

5. Por uma avaliação da qualidade que amplie o conceito de resultados para além das proficiências em testes padronizados, ampliando-se o leque de indicadores, promovendo e viabilizando iniciativas de avaliação institucional participativa e fortalecendo o caráter diagnóstico, pedagógico e formativo de avaliação na educação básica e na educação superior.

6. Pela gestão democrática da educação brasileira em todos os níveis, sistemas, instituições e com a ampliação da participação popular. 
7. Por uma educação socialmente referenciada construída sob a perspectiva do respeito aos direitos humanos e o diálogo com os movimentos sociais.

8. Pela liberdade de expressão no processo de educação e ensino contra o movimento 'Escola Sem Partido' e suas 'leis da mordaça'.

9. Pela garantia da concepção de educação básica constituída pelas etapas de educação infantil, ensino fundamental e médio assegurando as especificidades das diferentes modalidades, por meio de políticas de acesso, permanência e gestão - contra a instituição das reformas que o sujeitam qualquer nível, etapa ou modalidade da educação ao mercado.

10. Pela constituição de um EAD (Ensino à Distância) e de cursos com qualidade - contra a comercialização desregulamentada da educação e do ensino.

11. Pela valorização dos profissionais da educação (formação, carreira, salários, condições de trabalho) na rede pública e no setor privado - contra a crescente flexibilização nas contratações destes profissionais.

12. Pelo cumprimento da Lei do Piso Nacional e a garantia de Planos de Carreira para todos os trabalhadores em Educação Básica e Educação Superior.

13. Pela garantia de financiamento e efetivação das leis para o fortalecimento da educação pública e gratuita, em todos os níveis, etapas e modalidades - contra o congelamento de investimentos decorrente da emenda 95/2016.

14. Pela garantia de investimento público exclusivamente para o ensino público - contra o fortalecimento do setor privado com gastos públicos.

São fortalecidas as frentes de luta contra a privatização do ensino e pela defesa da utilização de verbas públicas para o ensino público, exclusivamente. Também, lutas pela valorização dos trabalhadores da educação e participação dos movimentos sociais na construção e políticas públicas, bem como pelo reconhecimento da diversidade, liberdade de expressão e práticas democráticas.

No que tange aO FONEC, foi realizado o encontro ampliado dos coletivos dos povos do campo que integram o referido Fórum, no mês de junho de 2018. Durante o encontro que debateu a conjuntura política e os 20 anos da Educação do Campo e do PRONERA foi produzida a Carta-Manifesto, explicitando princípios, resistência e compromissos do coletivo nacional, com o intuito de "[...] tornar pública nossa leitura sobre o atual momento político por que passa o País, seus efeitos sobre os direitos dos/ 
as trabalhadores, especialmente sobre a educação do povo do campo, das águas e das florestas e apresentar nossos compromissos e nossa agenda de lutas". (FONEC, 2018, p. 1)

A Carta-Manifesto é composta de 23 itens sobre a conjuntura política brasileira. Menciona-se a "crise estrutural da sociedade brasileira, com o aprofundamento do golpe imperialista, midiático-jurídico-parlamentar deflagrado em 2016"; critica-se o conjunto de "medidas econômicas liberais adotadas pelo governo atual, como a Emenda Constitucional no 95, que congela os investimentos totais do País para assegurar os lucros ao capital financeiro"; denuncia a "suspensão da política de Reforma Agrária" e o "desmonte da política de assistência técnica" aos povos do campo; denunciam-se os assassinatos no campo; também, denuncia o fato de que "a educação tem sido uma área prioritária para expansão dos interesses do capital em nosso país". O documento registra críticas à reforma do Ensino Médio mediante Medida Provisória 746/2016, aos cortes nas bolsas para estudantes indígenas e quilombolas, e à redução e interrupção de verbas para os programas COMO O PRONERA. (FONEC, 2018, p. 1 - 6)

Em síntese, em 23 itens, o documento traz uma radiografia crítica da conjuntura político-econômica do país, com demonstrativos dos retrocessos na esfera educacional e na formação sociopolítica da sociedade brasileira. São perdas para a classe trabalhadora do campo e da cidade, que se mantêm resistentes e em vigília permanente, em meio a disputas, confrontos e repressão policial. O documento também destaca conquistas havidas nos 20 anos da Educação do Campo, a exemplo dos programas PRONERA, Residência Agrária, Observatório da Educação do Campo, PRONACAMPO, PNLD-Campo, PIBID-Diversidade entre outros.

Dessa forma, o Movimento Nacional de Educação do Campo escreve capítulos na história da educação brasileira, por essas conquistas e por outras dispostas em documentos nacionais como as diretrizes nacionais para escolas do campo (Brasil, 2002 e 2008), e o decreto presidencial que dispõe sobre política de educação do campo e o PRONERA (Brasil, 2010).

O coletivo nacional no espaço público do FONEC continua na defesa do Projeto Popular para o Brasil. Reafirmam lutas também postas pelo FNEP, a saber: combater privatização da educação pública, atuar contra as reformas empresariais que estão sendo instituídas por meio da BNCC e da Reforma do Ensino Médio, afirmar a agroecologia como matriz tecnológica, princípio social e pedagógico, reafirmar que o fechamento de escolas é prática criminosa entre outros. (FONEC, 2018, p. 6-10).

São, portanto, dois sujeitos coletivos (FNEP e FONEC) que agregam movimento sociais, organizações, universidades, entidades acadêmico-científicas, sindicatos entre outros, e constituem espaços públicos para debate da sociedade e da educação brasileira, ao mesmo tempo que analisam 
conjuntura político-econômica e condicionantes estruturais históricos que fragilizam o avanço das lutas e conquistas da sociedade brasileira, como escreve Souza (2019, p. 21).

Há no Brasil centenas de sujeitos coletivos que contestam a desigualdade social, a concentração da renda e a face patrimonialista do Estado. Há disputas políticas e judiciais em torno de direitos sociais. O direito à educação, a liberdade de expressão e a autonomia universitária correm perigos, pois há um cenário político de fragilização de práticas democráticas. Cenário instalado na conjuntura de 2016 e que se fortalece com o governo federal de Jair Bolsonaro (2019 a 2022).

\section{Considerações finais}

Os seis anos em foco neste artigo revelam dois movimentos que disputam projetos societários. De um lado, um coletivo conservador que retoma os rumos da política determinada pelas relações econômicas do capital financeiro e clientelistas em âmbito da política nacional e local. Esse coletivo é formado pelos defensores do Projeto Escola Sem Partido, Movimento Brasil Livre (MBL) e por partidos conservadores, a exemplo do Partido Social Liberal (PSL), entre outros. De outro lado, um coletivo formado por sujeitos coletivos que pautam a educação como construção democrática e que resiste às decisões autoritárias que "reformam a educação" com vistas aos interesses privados, como é o caso do Movimento da Educação do Campo e do FNPE.

A conjuntura de 2013 a 2018 foi marcada por confrontos entre governos e sociedade civil (sujeitos coletivos da classe trabalhadora). Tais confrontos evidenciam disputas por projetos políticos. De um lado o que se denomina de Projeto Popular de País, em particular pelo FONEC, e de outro lado o projeto que retoma os princípios da política neoliberal vigentes na década de 1990, como salienta Souza (2019).

Na sociedade civil, os sujeitos coletivos constituíram-se em meio à repressão policial, ao cerceamento ideológico e à judicialização de questões vinculadas a direitos sociais. Resistiram ao Golpe de 2016 e às suas consequências no curto e médio prazo. Denunciam a criminalização dos movimentos sociais, a fragilização, precarização e flexibilização do trabalho docente, bem como aos cortes orçamentários de projetos educacionais.

São os sujeitos coletivos da classe trabalhadora, por meio de manifestações, cartas e ocupação de espaços públicos, que dão visibilidade à contradição maior que assola a sociedade brasileira (concentração da riqueza e do poder político $x$ aumento da desigualdade). São eles que expõe o projeto que desejam para o país, que lutam pela educação pública 
e contra o encolhimento da democracia. Os movimentos sociais e demais sujeitos coletivos enfrentam o desafio de reorganizar as pautas de luta e as condições infraestruturais para fazer frente ao projeto hegemônico em vigência, bem como reinventar as práticas democráticas na sociedade civil e na relação dela com a sociedade política.

\section{Referências}

Brasil. INEP. (2018). Censo da Educação Brasileira, Educação Superior. http://inep.gov.br/web/guest/sinopses-estatisticas-da-educacao-superior

Conape. (2017). Lançamento Conferência Nacional Popular de Educação. Manifesto em prol da democracia e da educação transformadora. Brasília, DF. https://www.cnte.org.br/images/stories/2017/ manifesto_de_lancamento_da_conapef.pdf

Conape. (2018). Regimento da etapa nacional CONAPE 2018. Belo Horizonte, MG. http://fnpe.com.br/docs/documentos/docs-conferencia/regimento-etapa-nacional-da-conape-2018-aprovado-aprovado-pleno-22-05-2018.pdf

Decreto $\mathrm{n}^{\circ} 7.352$ de 4 de novembro de 2010. (2010, 5 novembro). Dispõe sobre a política de Educação do Campo e o Programa Nacional de Educação na Reforma Agrária - Pronera. Diário Oficial da União, Poder Legislativo, Brasília, DF.

Emenda Constitucional n 95, Câmara dos Deputados e Senado Federal. (2016, 16 dezembro). Altera o Ato das Disposições Constitucionais Transitórias, para instituir o Novo Regime Fiscal, e dá outras providências. Diário Oficial da União, Brasília, DF.

Fórum Nacional de Educação do Campo. (2013). Relatório Síntese das conclusões e proposições da oficina de Planejamento 2013-2014. Brasília, DF.

Fórum Nacional de Educação do Campo. (2015). III Seminário Nacional. Documento Final. Brasília, DF.

Fórum Nacional de Educação do Campo. (2018). Carta - Manifesto 20 anos da Educação do Campo e do PrONERA. Brasília, DF.

Fórum Nacional Popular de Educação. (2018). Documento final: plano de lutas. Conape: Etapa Nacional: Lula Livre. Belo Horizonte, MG. http://fnpe.com.br/docs/documentos/docs-conferencia/fnpe-conape2018-documento-final-planodelutas.pdf

Gohn, M. da G. (1997). Teoria dos movimentos sociais: paradigmas clássicos e contemporâneos. Loyola.

Gohn, M. da G. (2003). Movimentos sociais e redes de mobilizações civis no Brasil contemporâneo. Vozes. 
Gohn, M. da G. (2013). Manifestações de junho de 2013 no Brasil e praças dos indignados no mundo. Vozes.

Gohn, M. da G. (2017). Movimentos sociais e lutas pela educação no Brasil: experiências e desafios na atualidade. In M. A. T. Campos, \& M. R. da Silva (Orgs.). Educação, movimentos sociais e políticas governamentais. (pp. 83 -92). Appris.

Gohn, M. da G. (2019). Participação e democracia no Brasil: da década de 1960 aos impactos pós-junho de 2013. Vozes.

Lei n ${ }^{\circ} 9.394$ de 20 de dezembro de 1996. (1996, 23 dezembro). Estabelece as diretrizes e bases da educação nacional. Diário Oficial da União, Poder Legislativo. http://www.planalto.gov.br/ccivil_03/leis/l9394.htm

Lei $n^{\circ} 13.005$ de 25 de junho de 2014. (2014, 26 junho). Aprova o Plano Nacional de Educação e dá outras providências. Diário Oficial da União, Poder Legislativo. http://www.planalto.gov.br/ccivil_03/_ ato2011-2014/2014/lei/l13005.htm

Lei $n^{\circ} 12.960$ de março de 2014. (2014, 28 março). Altera a Lei no 9.394, de 20 de dezembro de 1996, que estabelece as diretrizes e bases da educação nacional, para fazer constar a exigência de manifestação de órgão normativo do sistema de ensino para o fechamento de escolas do campo, indígenas e quilombolas. Diário Oficial da União. http://www.planalto.gov.br/ccivil_03/_Ato2011-2014/2014/ Lei/L12960.htm

Movimento Brasil Livre. (2015). Propostas aprovadas no $1^{\circ}$ Congresso Nacional do Movimento Brasil Livre. São Paulo. http://www.mbl.org.br

Munarim, A. (2008). Movimento Nacional de Educação do Campo: uma trajetória em construção. In $31^{a}$ Reunião Anual da ANPED, Caxambu/ MG. Recuperado a partir de http://31 reuniao.anped.org.br/1 trabalho/ GT03-4244--Int.pdf

Paludo, C. (2015). Educação Popular Como Resistência e Emancipação Humana. Cad. Cedes, 35, 219-238. http://dx.doi.org/10.1590/ CC0101-32622015723770

Portaria no 577, Ministério da Educação. (2017, 28 abril). Dispõe sobre o Fórum Nacional de Educação. Brasília. Diário Oficial da União. http:// fne.mec.gov.br/images/pdf/legislacao/portaria_577_27042017.pdf

Resolução CNE/CEB no 1 de 3 de abril de 2002. (2002, 9 abril). Institui Diretrizes Operacionais para a Educação Básica das Escolas do Campo. Diário Oficial da União, Poder Legislativo.

Resolução CNE/CEB n ${ }^{\circ} 2$ de 28 de abril de 2008. (2008, 29 abril). Estabelece diretrizes complementares, normas e princípios para o desenvolvimento de políticas públicas de atendimento da Educação Básica do Campo. Diário Oficial da União. 
Souza, M. A. de (2019). ANPEd: rumo a meio século de lutas por educação e democracia. Revista Brasileira de Educação, v. 24, 2019. https:// doi.org/10.1590/s1413-24782019240049

Souza, M. A. de. (2017). Ações coletivas e o direito à educação no Brasil: 1996 a 2016. In xxxı Congreso alas 2017, Montevideo.

Souza, M. A. de \& Beltrame, S. A. B. (2017). Movimentos sociais: Articulação com educação popular e com redes sociais digitais. In M. A. T. Campos \& M. R. da Silva, (Orgs.). Educação, movimentos sociais e políticas governamentais. (pp. 93 - 106). Appris.

Telles, V. da S. (2006). Direitos sociais: afinal do que se trata? Editora da UFMG.

Wanderley, L. E. W. (2000). A questão social no contexto da globalização: o caso latino-americano e o caribenho. In R. Castel, L. E. Wanderley \& M. Belfiore-Wanderley (2000). Desigualdade e a questão social (pp. 51 - 162). EDUC. 